\title{
Aroma production by Yarrowia lipolytica in airlift and stirred tank bioreactors: Differences in yeast metabolism and morphology
}

\author{
A. Braga ${ }^{a}$, D.P. Mesquita ${ }^{a}$, A.L. Amaral ${ }^{\mathrm{a}, \mathrm{b}}$, E.C. Ferreira ${ }^{\mathrm{a}}$, I. Belo ${ }^{\mathrm{a}, *}$ \\ a CEB - Centre of Biological Engineering, University of Minho, Campus de Gualtar, 4710-057 Braga, Portugal \\ b Instituto Politécnico de Coimbra, ISEC, DEQB, Rua Pedro Nunes, Quinta da Nora, 3030-199 Coimbra, Portugal
}

\section{A R T I C L E I N F O}

\section{Article history:}

Received 30 May 2014

Received in revised form 8 September 2014

Accepted 13 September 2014

Available online 22 September 2014

\section{Keywords:}

Airlift bioreactor

Y. lipolytica

$\gamma$-Decalactone

Oxygen mass transfer rate

Cellular morphology

Image analysis

\begin{abstract}
A B S T R A C T
The production of $\gamma$-decalactone from castor oil in batch cultures of Yarrowia lipolytica W29 was compared in stirred tank (STR) and airlift bioreactors. Oxygen mass transfer from air to biphasic medium was characterized in both bioreactors through correlations for $k_{L} a$ with power input and superficial gas velocity. Different conditions of oxygen transfer rate (OTR) were selected to perform biotransformations and for both bioreactors improvement of $\gamma$-decalactone productivity was obtained with OTR increase, with the highest value of $75 \pm 10 \mathrm{mg} \mathrm{L}^{-1} \mathrm{~h}^{-1}$ being obtained in the STR for a $k_{\mathrm{L}} a$ of $113 \pm 5 \mathrm{~h}^{-1}$. However, a 2-fold increase in $\gamma$-decalactone concentration (around $3 \mathrm{~g} \mathrm{~L}^{-1}$ ) was achieved in the airlift compared to STR. Morphological characterization of the yeast cells by quantitative image analysis techniques showed that pneumatic agitation causes less impact in the cells morphology than mechanical agitation. A predominance of somewhat loose cells and quite irregular structures was observed in the STR.
\end{abstract}

(C) 2014 Elsevier B.V. All rights reserved.

\section{Introduction}

In aerobic cultures using non-hydrosoluble substrates, such as the use of castor oil (CO) for the biotransformation of ricinoleic acid into $\gamma$-decalactone by Yarrowia lipolytica, the selection of bioreactor type is particularly important. Mass transfer phenomena in this complex system include the oxygen mass transfer from the gas to the liquid phases, between the liquid hydrophobic and aqueous phases, and from the liquid phases to the cells. In classical stirred tank bioreactors high shearing rates have been used to break down air bubbles and substrate globules, and thus increase the interfacial area for mass transfer [1-3]. Nevertheless, such agitation conditions tend to separate adhered substrate globules to cells which, in turn, can be prevented using aeration as the driving force promoting agitation (the principle behind airlift reactors). A few other disadvantages have been already found for stirred tanks: the degree of agitation required to achieve sufficient oxygen mass transfer may, at times, damage the microorganisms; the mechanical power input is high (leading to high operating costs), resulting in overheating. Furthermore, due to their complexity, stirred reactors are more expensive and less robust than other types of bioreactors. Thus,

\footnotetext{
* Corresponding author. Tel.: +351 253604413; fax: +351 253604429

E-mail address: ibelo@deb.uminho.pt (I. Belo).
}

other designs have been proposed and investigated since decades, among which airlift reactors [4].

Airlift bioreactors are pneumatically agitated and often employed in bioprocesses where gas-liquid transfer is important. Some attractive features of airlift bioreactors are the low power consumption, simplicity in construction with no moving parts, high mass and heat transfer rates and uniform shear distribution $[5,6]$.

The characterization of the oxygen mass transfer ability of each type of bioreactor is very important for its applicability in aerobic processes, being described by the volumetric oxygen mass transfer coefficient $\left(k_{L} a\right)$, a crucial parameter of bioprocesses scale-up. $k_{L} a$ depends on a large number of parameters: physical properties of gas and liquid phases, operating conditions and the bioreactor geometric design $[7,8]$. Several empirical correlations have been proposed to estimate $k_{L} a$ in STR [9] and in airlift bioreactors [7].

$Y$. lipolytica, one of the strictly aerobic most studied "nonconventional" yeast species, is able to use CO as substrate for $\gamma$-decalactone production, as the result of the peroxisomal $\beta$ oxidation of ricinoleic acid, the main fatty acid of $\mathrm{CO}$ [10]. In this $\beta$-oxidation pathway, aeration is a critical parameter especially concerning the accumulation of 3-hydroxy- $\gamma$-decalactone [11]. As an intervening factor in the metabolic pathway involved in this biotransformation, oxygen plays an important role in the reactions of production and consumption of the aroma [12].

$Y$. lipolytica is a dimorphic organism capable of growing in two distinct morphological forms, usually as single oval cells or as 


\begin{tabular}{|c|c|}
\hline \multicolumn{2}{|c|}{ Nomenclature } \\
\hline$D_{e q}$ & equivalent diameter $(\mu \mathrm{m})$ \\
\hline$k_{L} a$ & oxygen volumetric mass transfer coefficient $\left(\mathrm{h}^{-1}\right)$ \\
\hline 0 & $\begin{array}{l}\text { dissolved oxygen concentration within the reactor } \\
\left(\mathrm{mg} \mathrm{L}^{-1}\right)\end{array}$ \\
\hline$O^{S}$ & oxygen saturation concentration $\left(\mathrm{mg} \mathrm{L}^{-1}\right)$ \\
\hline OTR & oxygen transfer rate $\left(\mathrm{g} \mathrm{L}^{-1} \mathrm{~h}^{-1}\right)$ \\
\hline$P_{g}$ & power input to the aerated system (W) \\
\hline $\mathrm{rpm}$ & rotations per minute \\
\hline$t$ & time $(\mathrm{h})$ \\
\hline$V$ & volume $\left(\mathrm{m}^{3}\right)$ \\
\hline vs & superficial gas velocity $\left(\mathrm{m} \mathrm{s}^{-1}\right)$ \\
\hline \multicolumn{2}{|c|}{ Greek letters } \\
\hline$\alpha, \delta$ & non-linear model parameters to be \\
\hline
\end{tabular}

filamentous hyphae, reversibly. It is believed that the dimorphism of this yeast, as well as other species, is a mechanism to overcome stress conditions [13]. Thus, the yeast morphology is strongly influenced by the growth conditions (aeration, carbon and nitrogen sources, $\mathrm{pH}$, dissolved oxygen concentration in the medium, etc.) [14]. The system motion, ensured by mechanical mixing or induced circulation, may have a significant effect on cellular activities. The existence of short and large yeast cells, alongside filaments with high ramification frequency, under steady stirring conditions, has been reported in the literature, implying that the morphology of a given mycelium seems to be consistently influenced by the mixing conditions [15]. Although yeast cells may still grow in adverse conditions, morphological changes can be observed. Microscopy techniques, combined with image analysis, are regarded as quite useful tools for yeasts morphological characterization toward the enlightenment of the environmental conditions dependency.

Nowadays, the automatic analysis of numerical images captured by digital cameras allows for quickly extracting of quantitative information [16]. Thus, microscopy image analysis techniques have gained, during the last years, an unquestionable role in several fields of research regarding yeasts characterization [17,18]. Quantitative image analysis (QIA) procedures can provide valuable information about the biological processes, and allow for a monitoring tool to decide if a given action should be carried out in the system. However, to the authors' knowledge, QIA application has never been considered for studying the morphological changes in $Y$. lipolytica, regarding the use of different reactors configuration to favor $\gamma$-decalactone production.

The main goal of the presented study was to evaluate the influence of mixing and oxygen mass transfer conditions on $\gamma$ decalactone production by $Y$. lipolytica in biphasic culture medium with $\mathrm{CO}$ as substrate. The influence of mechanical and pneumatic agitation in the yeast cell morphology was also investigated using QIA.

\section{Experimental procedures}

\subsection{Microorganism, media and culture conditions}

Y. lipolytica W29 (ATCC20460) was cultured for $48 \mathrm{~h}$ on YPDA medium (agar $30 \mathrm{~g} \mathrm{~L}^{-1}$, glucose $20 \mathrm{~g} \mathrm{~L}^{-1}$, peptone $20 \mathrm{gL}^{-1}$, yeast extract $10 \mathrm{~g} \mathrm{~L}^{-1}$ ) at $27^{\circ} \mathrm{C}$ to inoculate (cell density of $0.5 \mathrm{~g} \mathrm{~L}^{-1}$ ) a $500 \mathrm{~mL}$ baffled Erlenmeyer flask containing $200 \mathrm{~mL}$ of glucose medium (YPD medium: glucose $20 \mathrm{~g} \mathrm{~L}^{-1}$, peptone $20 \mathrm{~g} \mathrm{~L}^{-1}$, yeast extract $10 \mathrm{~g} \mathrm{~L}^{-1}$ ). Flasks were incubated at $140 \mathrm{rpm}, 27^{\circ} \mathrm{C}$ for $19 \mathrm{~h}$. Cells from this pre-inoculum were harvested by centrifugation $(2442 \times \mathrm{g}, 10 \mathrm{~min})$ and used to inoculate $4.5 \mathrm{~L}$ of YPD medium in the airlift bioreactor and $1.7 \mathrm{~L}$ of YPD medium in STR bioreactor (RALF PLUS SOLO, Bioengineering, Switzerland), to obtain an initial cell concentration of $0.5 \mathrm{~g} \mathrm{~L}^{-1}$. After the cell growth phase (cell density of $30 \mathrm{~g} \mathrm{~L}^{-1}$ ), the components of the biotransformation medium were added to the culture, in order to start the biotransformation phase. The composition of the biotransformation medium was $6.7 \mathrm{~g} \mathrm{~L}^{-1} \mathrm{YNB}$ (yeast nitrogen base) with amino acids, $2.5 \mathrm{~g} \mathrm{~L}^{-1}$ $\mathrm{NH}_{4} \mathrm{Cl}, 30 \mathrm{~g} \mathrm{~L}^{-1} \mathrm{CO}$ and $3 \mathrm{~g} \mathrm{~L}^{-1}$ Tween 80 , respectively.

\subsubsection{Bioreactors}

Biotransformations were carried out in a $4.5 \mathrm{~L}$ operating volume in an internal concentric-tube airlift bioreactor with a $0.07 \mathrm{~m}$ inside diameter. The height of the riser-tube was $0.37 \mathrm{~m}$ with an inside diameter of $0.032 \mathrm{~m}$. Air was used as gas stream in the gasliquid contactor and introduced at the bottom of the bioreactor using a five holes sparger. The inlet gas flow-rate was measured and controlled with a mass flow controller (Alicat Scientific, USA). Cellular growth occurred at $27^{\circ} \mathrm{C}$, and $5 \mathrm{~L} \mathrm{~min}^{-1}$ aeration rate, for $48 \mathrm{~h}$. Biotransformations were carried out at $6 \mathrm{~L} \mathrm{~min}^{-1}, 7.5 \mathrm{~L} \mathrm{~min}^{-1}$ and $9 \mathrm{~L} \mathrm{~min}^{-1}$ aeration rates.

A STR bioreactor was also used (3.7 L operating volume, with $0.31 \mathrm{~m}$ height and $0.17 \mathrm{~m}$ diameter, and with Rushton impeller, 6blade, $0.06 \mathrm{~m}$ outside diameter) and cellular growth occurred at $27^{\circ} \mathrm{C}, 500 \mathrm{rpm}$ and $3 \mathrm{~L} \mathrm{~min}^{-1}$ aeration rate for $19 \mathrm{~h}$. Biotransformations were performed at pH 6 [19], air flow-rates of $1.7 \mathrm{~L} \mathrm{~min}^{-1}$ and $5.1 \mathrm{~L} \mathrm{~min}^{-1}$ at stirring speeds of $400 \mathrm{rpm}, 500 \mathrm{rpm}$ and $650 \mathrm{rpm}$.

\subsubsection{Oxygen mass transfer determination}

In the experiments without cells, the static gassing-out technique was used for the $k_{L} a$ determination [20]. During biotransformations $k_{L} a$ was determined using the dynamic gassing-out technique [21].

For $k_{L} a$ modeling, the data fitting to Eqs. (1) and (2) was performed by least-squares non-linear regression using the Solver tool of Microsoft Excel 2011 software.

$k_{L} a=\alpha\left(\frac{P_{g}}{V}\right)^{\delta}\left(v_{s}\right)^{\gamma}$

This equation was applied for data obtained in STR where $P_{g}$ represents the power input to the aerated bioreactor, $V$ the bioreactor working volume, $v_{s}$ the superficial gas velocity and $\alpha, \delta$ and $\gamma$ are dimensionless constants.

The power input to the aerated system $\left(P_{g}\right)$ was determined according to Rushton et al. [22] and Michel and Miller [23], taking into account that the flow regime inside the system is turbulent [24]. Also, according to Michel and Miller [23], the parameters of this empirical equation depends of systems geometry and was only valid for superficial gas velocity between 0.042 and $0.180 \mathrm{~m} \mathrm{~s}^{-1}$ and agitation rate between 180 and $960 \mathrm{rpm}$, that cover the conditions used in this work.

$k_{L} a=C v_{s}^{\alpha}$

Eq. (2) was applied for data obtained in the airlift where $v_{s}$ is the superficial gas velocity, and $C$ and $\alpha$ are dimensionless constants.

\subsection{Sampling and analytical methods}

Samples were collected throughout the monitoring period for yeast cells concentration and lactones quantification. Cell concentration was estimated by optical density measurements for cultures in YPD medium and by microscopic cell counting using a Neubauer-improved counting chamber [25] for cells in biotransformation medium, due to the oil interference in optical density measurements. Cellular viability was estimated by the methylene blue method [26]. Lactones were extracted from $2 \mathrm{~mL}$ samples with 
$2 \mathrm{~mL}$ diethyl ether, and the organic phase was analyzed by GC as previously described by Braga et al. [27].

The lipidic material was also visualized and analyzed by Nile blue A staining. The methodology was adapted from Ostle and Holt [28], by incubating $1 \mathrm{~mL}$ of sample (supernatant) with one drop of Nile blue A for $10 \mathrm{~min}$, and is further reported in Mesquita et al. [29]. Oil droplets were visualized using epifluorescence microscopy by means of an Olympus BX51 (Olympus, Tokyo, Japan) fluorescence microscope at $400 \times$ total magnification.

\subsection{Image analysis}

\subsubsection{Samples preparation}

During the monitoring period, samples were also collected for morphological characterization using QIA in bright-field microscopy. $1 \mathrm{~mL}$ of each sample was collected and centrifuged at $5000 \mathrm{rpm}$ for $5 \mathrm{~min}$. The supernatant was discarded and the pellet cells were washed and re-suspended with distilled water and centrifuged using the same conditions. This procedure was repeated three times in order to remove all lipidic material. The pellet cells were then re-suspended in $1 \mathrm{~mL}$ of distilled water. Afterwards, samples were combined with the same volume of safranin $O(0.25 \% \mathrm{v} / \mathrm{v}$, Panreac) and then visualized in bright-field microscopy.

\subsubsection{Bright-field image acquisition}

The safranin stained yeast cells were observed by means of an Olympus BX51 (Olympus, Tokyo, Japan) optical microscope, at $400 \times$ magnification, coupled with an Olympus DP25 (Olympus, Tokyo, Japan) digital camera. Image acquisition was further performed according to Mesquita et al. [30].

\subsubsection{Bright-field image analysis}

The image processing and analysis was based on the identification, quantification, and morphological characterization of yeast cells using Matlab 7.8.0 (The Mathworks, Natick, MA). A detailed description of the developed image processing and analysis program is presented below.

The first step of the QIA procedure was based on the enhancement of the color images by background removal. In this stage the original image was first divided by a previous acquired background image to minimize background light differences. Afterwards, the resulting RGB image was split into the three composing channels (red, green and blue), and the segmentation took place using the image of the minima of the three channels. Next, objects connected to the image border as well as small debris were suppressed. Furthermore, the application of hole-fill procedure, and distance based morphological operations was further used, to fill object holes and enhance the borders definition. The resulting binary image was further used for characterization, upon the isolation of individual cells. The yeast cells were classified according to their size, based on the equivalent diameter $\left(D_{e q}\right)$ in small $\left(D_{e q}<2 \mu \mathrm{m}\right)$, intermediate $\left(2 \mu \mathrm{m}<D_{e q}<10 \mu \mathrm{m}\right)$ and large cells $\left(D_{e q}>10 \mu \mathrm{m}\right)$. For each size several morphological parameters were determined for cell characterization, supported in the previous study of Amaral and Ferreira [31] and Mesquita et al. [32].

\section{Results and discussion}

\subsection{Oxygen mass transfer in airlift and STR bioreactors}

Mass transfer modeling in biphasic systems has been conducted by several authors [33,34]. Biphasic systems have been used to improve mass transfer from the gas to the aqueous phase, where the second liquid phase (organic) is usually an inert compound, like perfluorocarbons and silicone oils, among others [1]. On the other hand, several biotechnological processes have been developed in
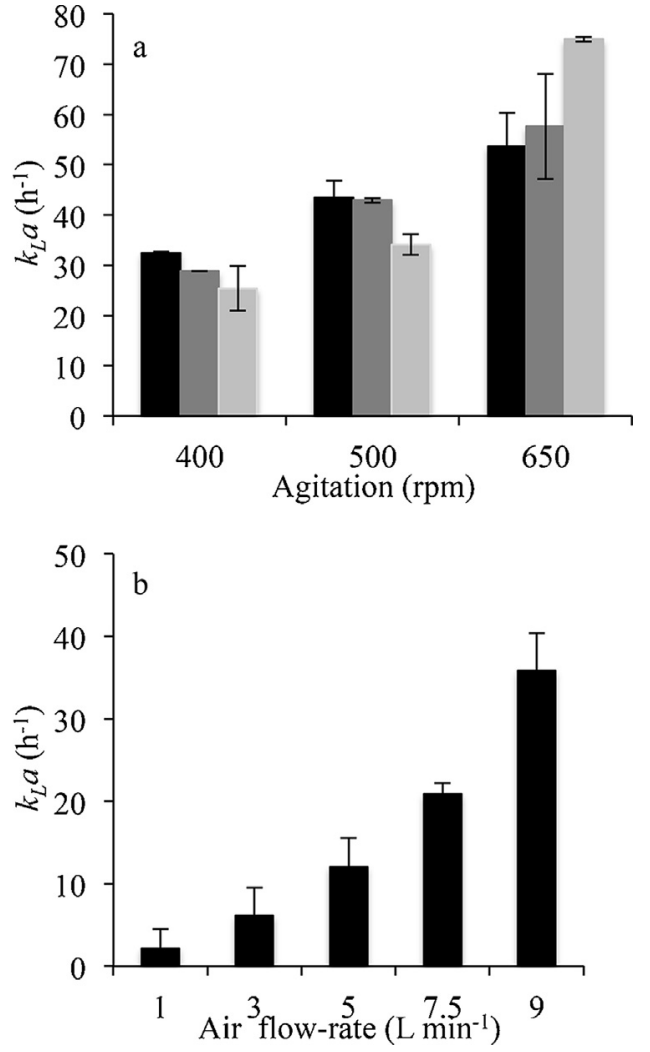

Fig. 1. Experimental $k_{L} a$ values at various experimental conditions in (a) STR, air

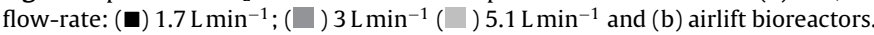

biphasic systems formed by an oil-in-water emulsion, in which the oil is the substrate to be degraded by microorganisms.

This is the case of $\gamma$-decalactone production by $Y$. lipolytica where the culture medium is an oil-in-water emulsion composed of castor oil, or its derivatives, stabilized by Tween 80 . In two-liquid phase systems, with the organic phase dispersed in the aqueous phase, the effect of the organic compound concentration on $k_{L} a$ can be taken into account [33] that was not applied in this work since constant oil concentration was used.

Experimental results of $k_{L} a$ obtained for the different experimental conditions investigated in STR and airlift bioreactors are depicted in Fig. 1a and b, respectively.

From the results in Fig. 1a it is possible to observe that for the STR, increasing the agitation from $400 \mathrm{rpm}$ to $650 \mathrm{rpm}$ and aeration rates from $1.7 \mathrm{~L} \mathrm{~min}^{-1}$ to $5.1 \mathrm{~L} \mathrm{~min}^{-1}$ resulted in a 2.3 -fold increment of the $k_{L} a$. It was also found that the agitation was the most important factor affecting $k_{L} a$, since its increase from $400 \mathrm{rpm}$ to $650 \mathrm{rpm}$, at constant air flow-rate of $5.1 \mathrm{~L} \mathrm{~min}^{-1}$, led to a 2.9 -fold increase in $k_{L} a$. This behavior is in agreement with the results of Amaral et al. [35], Gomes et al. [33] and Gómez-Diaz and Navaza [36] which showed that $k_{L} a$ depends more strongly on agitation than on aeration rates. In the STR, the increase of aeration had no significant effect in $k_{L} a$ values $(p<0.05)$ for the lower agitation speeds (see Fig. 1a). This is due to the fact that increasing mixing induces the fine dispersion of air bubbles in the biotransformation medium, thus resulting in the gas-liquid interfacial area increase. Also, for lower OTR conditions the mixture low efficiency can lead to limitations in the homogenization of the medium and consequently affect oxygen mass transfer. In the airlift bioreactor (Fig. 1b), the aeration rate had a strong impact in $k_{L} a$ since an increment of the air flow-rate from $1 \mathrm{~L} \mathrm{~min}^{-1}$ to $9 \mathrm{~L} \mathrm{~min}^{-1}$ resulted in a 16.3 -fold increase of the $k_{L} a$. This observation is in agreement with previous experimental works [37-42]. Comparing both reactors, for the 
Table 1

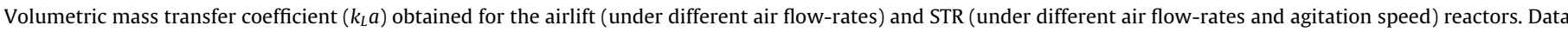
are presented as the mean and standard deviation of two independent experiments.

\begin{tabular}{|c|c|c|c|c|c|}
\hline \multicolumn{3}{|l|}{ Airlift } & \multicolumn{3}{|l|}{ STR } \\
\hline Air flow-rate $\left(\mathrm{L} \mathrm{min}^{-1}\right)$ & $k_{L} a\left(\mathrm{~h}^{-1}\right)$ & $\begin{array}{l}\text { Productivity } \\
\left(\mathrm{mg} \mathrm{L}^{-1} \mathrm{~h}^{-1}\right)\end{array}$ & $\begin{array}{l}\text { Agitation and } \\
\text { air flow-rate }\end{array}$ & $k_{L} a\left(\mathrm{~h}^{-1}\right)$ & $\begin{array}{l}\text { Productivity } \\
\left(\mathrm{mg} \mathrm{L}^{-1} \mathrm{~h}^{-1}\right)\end{array}$ \\
\hline 6 & $16 \pm 4$ & $29 \pm 4$ & $\begin{array}{l}400 \mathrm{rpm} \\
1.7 \mathrm{~L} \mathrm{~min}^{-1}\end{array}$ & $39 \pm 3$ & $16 \pm 6$ \\
\hline 7.5 & $21 \pm 3$ & $39 \pm 7$ & $\begin{array}{l}500 \mathrm{rpm} \\
5.1 \mathrm{~L} \mathrm{~min}^{-1}\end{array}$ & $69 \pm 3$ & $31 \pm 8$ \\
\hline 9 & $35 \pm 3$ & $65 \pm 9$ & $\begin{array}{l}650 \mathrm{rpm} \\
5.1 \mathrm{~L} \mathrm{~min}^{-1}\end{array}$ & $113 \pm 5$ & $75 \pm 10$ \\
\hline
\end{tabular}

tested conditions and similar air flow-rates, higher $k_{L} a$ values were observed for the STR with respect to the airlift bioreactor.

A number of empirical correlations have been proposed to estimate $k_{L} a$ values in different reactor types. Dimensional equations establish relationships between $k_{L} a$ and superficial gas velocity, fluid properties and bioreactor geometry (mainly column height and diameter, and sparger characteristics), although the last ones present relatively little influence. The STR dataset (Fig. 1a) was fitted by Eq. (1) resulting in Eq. (3) and from the airlift dataset (Fig. 1b) was fitted by Eq. (2) resulting in Eq. (4).

$k_{L} a=(18 \pm 11)\left(\frac{P_{g}}{V}\right)^{0.51 \pm 0.08} v_{s}^{0.24 \pm 0.11}$

$k_{L} a=(759 \pm 45) v_{s}^{1.85 \pm 0.13}$

For the empirical equation (3), the $P_{g} / V$ range from 30.7 to $163.4 \mathrm{~W} \mathrm{~m}^{-3}$ and $v$ s from 0.0023 to $0.0069 \mathrm{~m} \mathrm{~s}^{-1}$. The $v s$ range from 0.021 to $0.187 \mathrm{~m} \mathrm{~s}^{-1}$, in Eq. (4).

For the airlift the predicted $k_{L} a$ was $1.03 \pm 0.09$ the experimental $k_{L} a$, and for the STR the predicted $k_{L} a$ was $0.84 \pm 0.08$ the experimental $k_{L} a$, showing that Eqs. (3) and (4) allow for a good estimation of the real $k_{L} a$ values. Given the obtained regression coefficients $\left(R^{2}\right)$ of 0.86 and 0.98 , for STR and airlift respectively, it could be concluded that Eq. (3) is a worse fitting of data than Eq. (4).

From Eq. (3) it can be observed that $k_{L} a$ depends on a power function of 0.51 with the specific power input $\left(P_{g} / V\right)$ and on a power function of 0.24 with the superficial gas velocity $(v s)$. The obtained power coefficients confirm that $k_{L} a$ depends strongly on the specific power input than on the superficial gas velocity, given the lower vs power coefficient. According to Kawase and MooYoung [43], for aqueous systems, the suggested values for $\delta$ (Eq. (1)) are between 0.37 and 0.80 , while, for $\gamma$ (Eq. (1)), the values are between 0.4 and 0.84 . Comparing the obtained values with the ones previously described in the literature, it was found that $\delta$ was within the range specified by Kawase and Moo-Young [43]. However, for $\gamma$ the found value was lower. It should be kept in mind though, that those studies were performed in water systems and this work described a biphasic system. In fact, Sauid et al. [44] studied the oxygen mass transfer in a biphasic system with palm oil and observed that the presence of vegetable oil could increase the $k_{L} a$ and, depending on the oil fraction added to the medium, alter the $\gamma$ exponent between 0.12 and 0.34 . These values indicate that the functional dependence of $k_{L} a$ on operating conditions for two-phase systems is slightly different from single-phase systems. Furthermore, it reinforces the $k_{L} a$ dependence on agitation, a very important factor to increase the organic phase dispersion in the aqueous phase, improving gas-liquid mass transfer [1].

According to Bello et al. [45] and Barboza et al. [46], for aqueous systems, the suggested values for $v s$ exponent in Equation 4, ranges between 0.5 and 1.3 , slightly lower than the 1.85 us value obtained in the current study.

\section{2. $\gamma$-Decalactone production}

From the studied set of conditions, biotransformations experiments were performed for selected OTR conditions in airlift and STR bioreactors.

From Table 1 it is clearly observed that $k_{L} a$ has a positive influence on aroma productivity, for both bioreactors. The increase in $\gamma$-decalactone productivity is a consequence of the increase in the production rate and not on the maximum aroma concentration obtained (Fig. 2). In fact, Fig. 2a indicates a maximum $\gamma$-decalactone concentration of $2.9 \pm 0.1 \mathrm{~g} \mathrm{~L}^{-1}$, obtained at $104 \mathrm{~h}$ with the lower OTR used $\left(6 \mathrm{~L} \mathrm{~min}^{-1}\right)$ for the biotransformation in the airlift. The
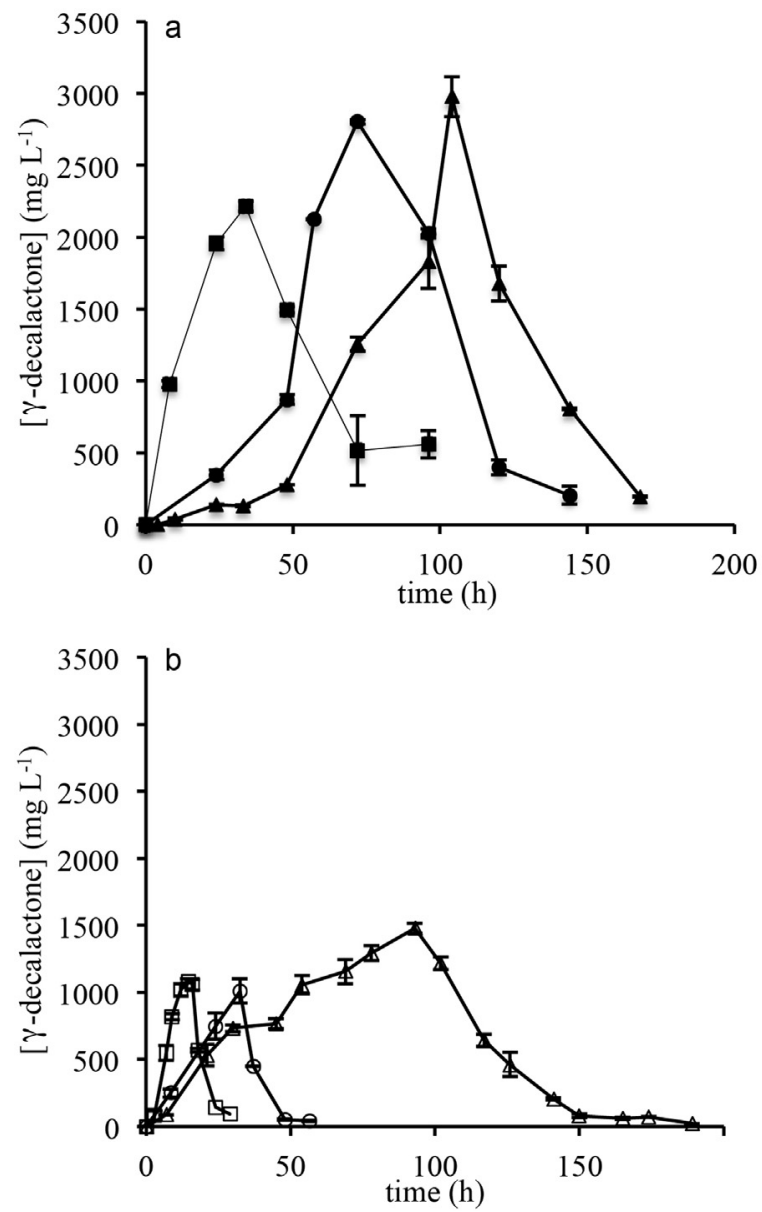

Fig. 2. Accumulation of $\gamma$-decalactone in the biotransformation medium under

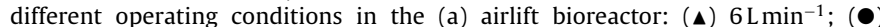
$7.5 \mathrm{~L} \mathrm{~min}^{-1} ;(\mathbf{\square}) 9 \mathrm{~L} \mathrm{~min}^{-1}$ and in (b) STR: $(\triangle) 400 \mathrm{rpm}$ and $1.7 \mathrm{~L} \mathrm{~min}^{-1}$; (○) $500 \mathrm{rpm}$ and $5.1 \mathrm{Lmin}^{-1}$; ( $\square$ ) $650 \mathrm{rpm}$ and $5.1 \mathrm{~L} \mathrm{~min}^{-1}$. Data are presented as mean and standard deviation of two independent experiments. Adapted with permission from Braga and Belo [19]. 
same behavior is shown in Fig. 2b, with the maximum aroma concentration $\left(1.5 \pm 0.4 \mathrm{~g} \mathrm{~L}^{-1}\right)$ obtained for the lower oxygen transfer tested $\left(1.7 \mathrm{~L} \mathrm{~min}^{-1}\right.$ and $\left.400 \mathrm{rpm}\right)$ in the STR.

Increasing the oxygen transfer rate reduces the time needed to reach the peak of $\gamma$-decalactone production, resulting in higher productivities than the ones obtained using low oxygenation conditions (Table 1). This is in agreement with the results obtained by Aguedo et al. [47] and García et al. [48]. Both works concluded that low oxygen concentrations in the medium induce the control of the $\beta$-oxidation pathway by acyl-CoA oxidase and therefore, an accumulation of $\gamma$-decalactone occurs.

Gomes [49] studied the $\gamma$-decalactone production from methyl ricinoleate in airlift bioreactors and observed that an increase on the oxygen transfer rate led to inversely proportional aroma concentrations, obtaining $1 \mathrm{~g} \mathrm{~L}^{-1}$ aroma with an air flow-rate of $1 \mathrm{~L} \mathrm{~min}^{-1}$. This fact was partly attributed to the Perspex airlift reactor used by Gomes [49]. In fact, the use of Perspex leaded to cell adhesion on the reactor surface, thus lowering the amount of "viable" cells in the biotransformation medium for efficient substrate utilization. Furthermore, when the adhered cells form a biofilm, oxygen mass transfer may be further reduced within it.

Comparing the results obtained for the two bioreactors, higher aroma concentrations were obtained for the airlift, although needing larger times for maximum $\gamma$-decalactone production. On the other hand, in the STR for higher oxygen transfer rate, the process was very fast, with maximum aroma production at $12 \mathrm{~h}$, a full $24 \mathrm{~h}$ earlier than in the airlift.

Also, in STR bioreactor, for low oxygen transfer rate, a complete depletion of dissolved oxygen was observed. In contrast, when using high agitation and aeration rates a stable dissolved oxygen concentration, between $40 \%$ and $60 \%$, was observed throughout the experiment. In airlift bioreactor, contrarily to STR, a stable dissolved oxygen concentration, between $30 \%$ and $50 \%$, was observed in all experiments.

3-Hydroxy- $\gamma$-decalactone production was also analyzed since, as previously described, the accumulation of this compound can provide useful information concerning the $\beta$-oxidation metabolic pathway control. According to Fig. 3, in general, the production of this lactone was inverse to $\gamma$-decalactone: higher oxygen transfer rate led to higher concentrations.

The increase of 3-hydroxy- $\gamma$-decalactone concentration in the medium was also dependent on oxygen transfer, in agreement with the results from Aguedo et al. [47] who observed that 3hydroxyacyl-CoA dehydrogenase was induced by high oxygen levels, resulting in an accumulation of this lactone. Furthermore, Garcia et al. [48] have also reported this compound synthesis for high OTR conditions. Higher 3-hydroxy- $\gamma$-decalactone concentrations were obtained in the present work, regarding the study of Garcia [50] on 3-hydroxy- $\gamma$-decalactone production in an airlift bioreactor $\left(1.5 \mathrm{~g} \mathrm{~L}^{-1}\right.$ at $\left.0.493 \mathrm{vvm}\right)$. As above mentioned, the used Perspex based reactor may have induced cells to adhere to the reactor surface, lowering the cells in the biotransformation medium, and possibly forming a biofilm with limited oxygen transfer.

Comparing the results obtained for the two bioreactors it is possible to observe higher hydro-lactone concentrations for the STR.

Despite of similar productivity values in both bioreactors (Table 1 ), although these values were obtained at lower $k_{L} a$ values in airlift bioreactor, the hidden effect of mixture could play an important role and mask the differences observed.

Due to the limited solubility of oil in water, cells growth in a medium containing lipids is influenced by the size of the oil droplets [51]. Thus, the oil droplets size on the emulsion, can strongly affect aroma production. Observations of oil droplets during its biotransformation by $Y$. lipolytica showed a quite dissimilarity between airlift and STR bioreactors (Fig. 4). It was found that larger oil droplets were obtained with the lower air flow-rate for the
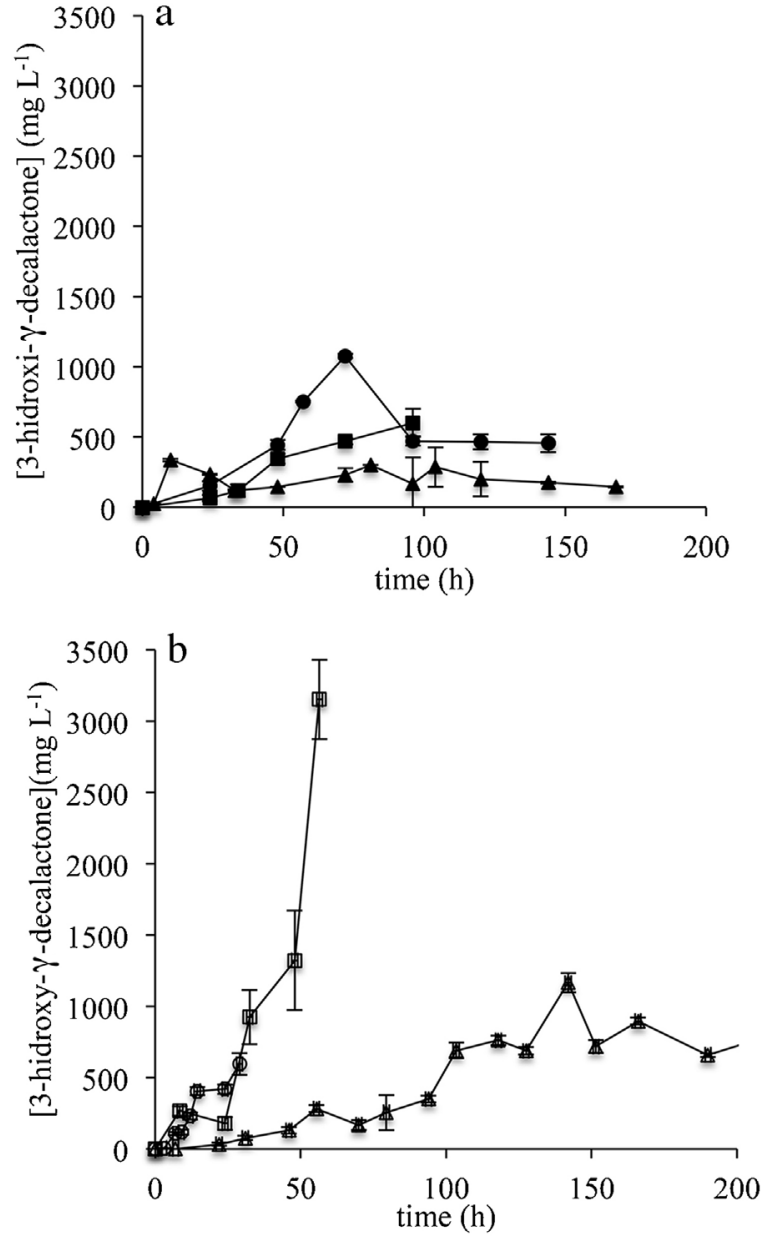

Fig. 3. Accumulation of 3-hydroxy- $\gamma$-decalactone in the biotransformation medium

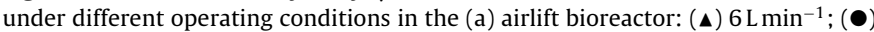
$7.5 \mathrm{~L} \mathrm{~min}^{-1} ;(\mathbf{\square}) 9 \mathrm{~L} \mathrm{~min}^{-1}$ and in (b) STR: $(\Delta) 400 \mathrm{rpm}$ and $1.7 \mathrm{~L} \mathrm{~min}^{-1} ;(\bigcirc) 500 \mathrm{rpm}$ and $5.1 \mathrm{Lmin}^{-1}$; ( $\left.\square\right) 650 \mathrm{rpm}$ and $5.1 \mathrm{~L} \mathrm{~min}^{-1}$. Data are presented as mean and standard deviation of two independent experiments.

airlift bioreactor $\left(6 \mathrm{~L} \mathrm{~min}^{-1}\right)$ (Fig. 4a) when compared to the STR for all tested conditions (Fig. 4d-f). Furthermore, it was found that the air flow-rate increase in the airlift led to smaller oil droplets (Fig. 4b and c), thus increasing mixture. On the other hand, for the STR the increase on the aeration and agitation rates seemed to have no significant impact on the oil droplets size, leading in all cases to small oil droplets, indicative of a good mixture.

Previous studies from Aguedo et al. [51] revealed that the contact between cells and droplets occurs mainly through the adhesion of small-sized droplets on the surface of the yeast. In the present case, after microscopic visual inspection, it was found that smaller CO droplets increase the aroma production rate. This corroborates the theory that the cells contact with the substrate occurs by the adsorption of small oil droplets in the cell surface.

Another possible explanation for the differences observed in the two systems is the impact of mechanical mixing or induced circulation in the cell morphology. Thus, the study of cell morphological and size changes, through microscopy and image analysis techniques, enables a better understanding of cellular adaptation mechanisms [52,53].

In all experiments, no significant cellular growth occurred during biotransformations and the viability of the cells remained practically constant at 95\% during the whole experiments.

In this study, QIA was used to investigate possible morphological changes in $Y$. lipolytica cells caused by the increase of the 

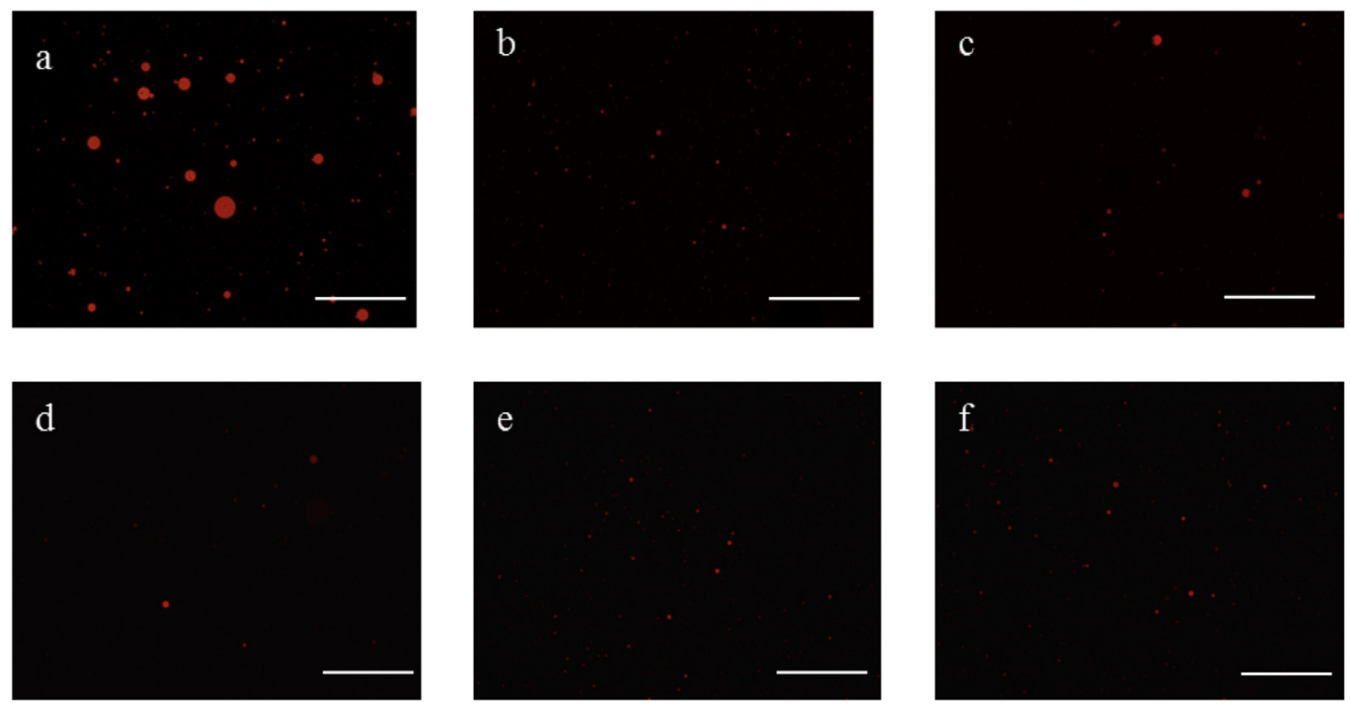

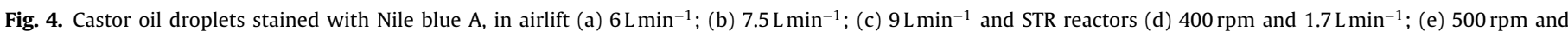
$5.1 \mathrm{~L} \mathrm{~min}^{-1}$; (f) $650 \mathrm{rpm}$ and $5.1 \mathrm{~L} \mathrm{~min}^{-1}$. The scale bar represents $50 \mu \mathrm{m}$.

air flow-rate, and to compare between mechanical and pneumatic mixing. In Fig. 5 images of Y. lipolytica cells in airlift and STR reactors are presented. It is possible to observe that in STR experiments pseudo-hyphae form of the cells increased with respect to the airlift. This result indicates that mechanical agitation may cause increased stress in the cells with respect to pneumatic agitation. These results are in agreement with the work of Kawasse et al. [13] showing that $Y$. lipolytica under thermal and oxidative stress increased hyphae formation, as a cell mechanism response to stress conditions. Also the effect of low dissolved oxygen was previously reported by Cruz et al. [14] in dimorphic yeasts as a stress factor causing the conversion from oval cells to hyphae.

Taking into account the information provided by image analysis, it is known that the equivalent diameter $\left(D_{e q}\right)$ is a size related variable; compactness represents the space fulfilling ability; eccentricity the elongation of the object, and robustness conjugates the fulfilling ability and the border's roughness [31]. In previous studies, it has been already found the usefulness of evaluating different cell size classes using image analysis information $[17,18]$. In the current work, $Y$. lipolytica cells were divided in three classes, with respect to the equivalent diameter: below $2 \mu \mathrm{m}$, between 2 and $10 \mu \mathrm{m}$, and above $10 \mu \mathrm{m}$. The larger size class was considered to represent attached cells; the intermediate size class was composed by normal cells and the smaller size class configured individual bud cells (after the release from the budding cell). The equivalent diameter of each cell class was evaluated to survey the effect of the reactor configuration in the cells size. First, a comparison was performed concerning the $D_{e q}$ behavior for each bioreactor. It was found that the $D_{e q}$ obtained for each size class and for both reactor configurations was kept constant during the monitoring period and in average around $8.1 \mu \mathrm{m}$ (data not shown). Thus, only average results were further considered since no substantial differences were observed when the three classes were analyzed separately.

An in-depth analysis was then performed regarding the morphological characteristics of the cells. The cells morphological characterization (Fig. 6) revealed that when the airlift bioreactor was operated with air flow-rate of $6,7.5$ and $9 \mathrm{Lmin}^{-1}$, no significant dissimilarities were obtained, indicating that the aeration provided as the driving force to promote agitation favored the presence of compact (high robustness values around 0.81), regular (high compactness values around 0.86 ), and somewhat elongated cells (eccentricity values around 0.68 ).

The analysis of the most significant morphological parameters of the STR (for $650 \mathrm{rpm}$ and $5.1 \mathrm{~L} \mathrm{~min}^{-1}$ ), showed a predominance of somewhat less compact (lower values of 0.75 for compactness), more elongated (higher eccentricity values around 0.77 ), and more irregular cells (lower robustness values around 0.72). This indicated that the cells could also be mechanically more fragile. Thus, it could be established, by the cells morphological characterization based on QIA, that pneumatic agitation should be preferred in the present case and that mechanical agitation caused a fair amount of stress to the cells.
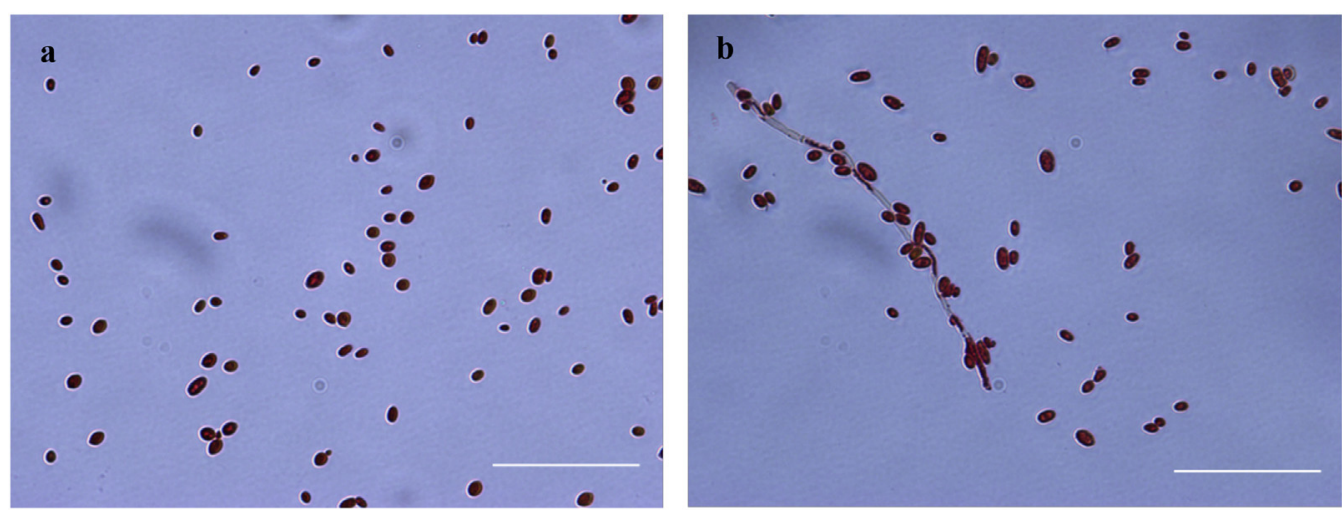

Fig. 5. Yarrowia lipolytica cells stained with safranin in (a) airlift bioreactor and (b) STR. The scale bar represents $50 \mu \mathrm{m}$. 

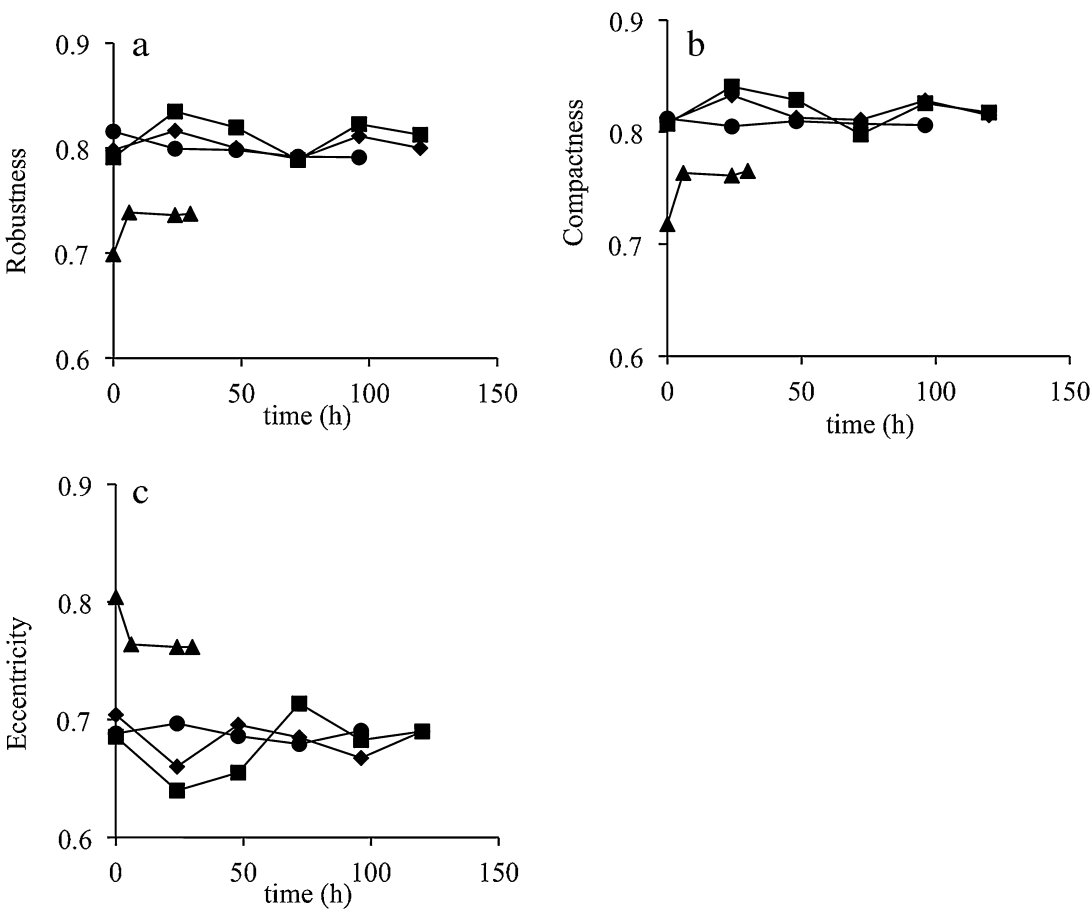

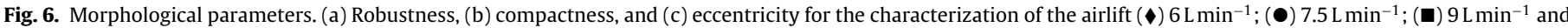
(৯) STR reactors.

\section{Conclusion}

$\gamma$-Decalactone production from castor oil by Y. lipolytica W29 has been studied in an STR and an airlift bioreactor, taking into account the effect of oxygen transfer rate and bioreactor design. Independently of the bioreactor type, OTR increase improved $\gamma$ decalactone production rate but decreased the maximum aroma concentration achieved. A maximum $\gamma$-decalactone concentration of around $3 \mathrm{~g} \mathrm{~L}^{-1}$ was obtained in the airlift for lower $k_{L} a$ values. Applying QIA techniques for cell morphological characterization it was possible to show that in airlift bioreactor cells were more compact, regular and somewhat elongated contrarily to STR, where cells were less compact, more elongated and irregular. Thus, the use of airlift bioreactors, which do not require mechanical agitation, a major cause of shear stress to the cells, may offer an alternative system for $\gamma$-decalactone larger scale production using $Y$. lipolytica.

\section{Acknowledgements}

The authors thank the Project 'BioInd - Biotechnology and Bioengineering for improved Industrial and Agro-Food processes, REF. NORTE-07-0124-FEDER-000028' co-funded by the Programa Operacional Regional do Norte (ON.2 - O Novo Norte), QREN, FEDER, "BioEnv - Biotechnology and Bioengineering for a sustainable world", REF. NORTE-07-0124-FEDER-000048, co-funded by the Programa Operacional Regional do Norte (ON.2 - O Novo Norte), QREN, FEDER and Fundação para a Ciência e a Tecnologia (FCT) (SFRH/BD/63701/2009 PhD grant to Adelaide Braga and SFRH/BPD/82558/2011 post-doctoral grant to Daniela Mesquita) for the financial support provided and FCT Strategic Project PEstOE/EQB/LA0023/2013.

\section{References}

[1] E. Dumont, H. Delmas, Mass transfer enhancement of gas absorption in oil-inwater systems: a review, Chem. Eng. Process. 42 (2003) 419-438.

[2] F. Yoshida, T. Yamane, M. Miyamoto, The increase oxygen diffusion rates in broths adding organic substrates, Ind. Eng. Chem. Proc. Des. Dev. 9 (1970) 570-577.
[3] J.L. Rols, G. Goma, Enhancement of oxygen transfer rates in fermentation using oxygen-vectors, Biotechnol. Adv. 7 (1989) 1-8.

[4] M.Y. Chisti, Airlift Bioreactors, Elsevier Science Publishers, Ltd., England, 1989.

[5] Y. Chisti, M. Moo-Young, On the calculation of shear rate and apparent viscosity in airlift and bubble column bioreactors, Biotechnol. Bioeng. 34 (1989) 1391-1392.

[6] J.C. Merchuk, N. Ladwa, A. Cameron, M. Bulmer, A. Pickett, Concentric-tube airlift reactors: effects of geometrical design on performance, AIChE J. 40 (1994) 1105-1117.

[7] F. Garcia-Ochoa, E. Gomez, Bioreactor scale-up and oxygen transfer rate in microbial processes: an overview, Biotechnol. Adv. 27 (2009) 153-176.

[8] S. Suresh, V.C. Srivastava, I.M. Mishra, Techniques for oxygen transfer measurement in bioreactors: a review, J. Chem. Technol. Biotechnol. 84 (2009) 1091-1103.

[9] F. Garcia-Ochoa, E. Gomez, Prediction of gas-liquid mass transfer in sparged stirred tank bioreactors, Biotechnol. Bioeng. 92 (2005) 761-772.

[10] M.A.Z. Coelho, P.F.F. Amaral, I. Belo, Yarrowia lipolytica: an industrial workhorse, in: A. Mendez-Vilas (Ed.), Current Research, Technology and Education Topics in Applied Microbiology and Microbial Biotechnology, 2010, pp. 930-944.

[11] Y. Waché, Y. Pagot, J.-M. Nicaud, J.-M. Belin, Acyl-CoA oxidase, a key step for lactone production by Yarrowia lipolytica, J. Mol. Catal. B: Enzym. 5 (1998) $165-169$.

[12] F. Thevenieau, J.-M. Nicaud, C. Gaillardin, Applications of the non-conventional yeast Yarrowia lipolytica, in: G. Kunze, T. Satyanarayana (Eds.), Yeast Biotechnology: Diversity and Applications, Springer, Dordrecht, the Netherlands, 2009 pp. 590-613.

[13] F.M. Kawasse, P.F. Amaral, M.H.M. Rocha-Leão, A.L. Amaral, E.C. Ferreira, M.A.Z Coelho, Morphological analysis of Yarrowia lipolytica under stress conditions through image processing, Bioprocess. Biosyst. Eng. 25 (2003) 371-375.

[14] J.M. Cruz, J.M. Dominguez, H. Dominguez, Dimorphic behavior of Debaryomyces hansenii grown on barley bran acid hydrolyzates, Biotechnol. Lett. 22 (2000) 605-610.

[15] B.C. Buckland, K. Gbewonyo, D. DiMasi, G. Hunt, G. Westerlield, A.W. Nienow, Improved performance in viscous mycelial fermentations by agitator retrofitting, Biotechnol. Bioeng. 31 (1988) 737-742.

[16] M.N. Pons, H. Vivier, Beyond filamentous species, Adv. Biochem. Eng. Biotechnol. 60 (1998) 61-93.

[17] M.A.Z. Coelho, I. Belo, R. Pinheiro, A.L. Amaral, M. Mota, J.A.P. Coutinho, E.C. Ferreira, Effect of hyperbaric stress on yeast morphology: study by automated image analysis, Appl. Microbiol. Biotechnol. 66 (2004) 318-324.

[18] M.A.Z. Coelho, J.A.P. Coutinho, E.C. Ferreira, M. Mota, I. Belo, Analysis of the effects of hyperbaric gases on S. cerevisiae cell cycle through a morphological approach, Process Biochem. 42 (2007) 1378-1383.

[19] A. Braga, I. Belo, Production of $\gamma$-decalactone by Yarrowia lipolytica: insights into experimental conditions and operating mode optimization, J. Chem. Technol. Biotechnol. (2014), http://dx.doi.org/10.1002/jctb.4349.

[20] W. Wise, The measurement of the aeration of culture media, J. Gen. Microbiol. 5 (1951) 167-177. 
[21] H. Taguchi, A. Humphrey, Dynamic method of the volumetric oxygen transfer coefficient in the fermentation systems, J. Ferm. Technol. 44 (1966) 881-889.

[22] J.H. Rushton, E.W. Costich, H.J. Everett, Power characteristics of mixing impellers: part I, Chem. Eng. Prog. 46 (1950) 395-404.

[23] B.J. Michel, S.A. Miller, Power requirements of gas-liquid agitated systems, AIChE J. 8 (1962) 262-266.

[24] M.N.H.Z. Alam, F. Razali, Scale-up of stirred and aerated bioengineering-bioreactor based on constant mass transfer coefficient, J. Technol. 2005 (2007) 95-110.

[25] J.P. Mather, P.E. Roberts, Introduction to Cell and Tissue Culture: Theory and Technique, Plenum Press, New York, 1998.

[26] A. Bonora, D. Mares, A simple colorimetric method for detecting cell viability in cultures of eukaryotic microorganisms, Curr. Microbiol. 7 (1982) 217-221.

[27] A. Braga, N. Gomes, J.A. Teixeira, I. Belo, Lipase induction in Yarrowia lipolytica for castor oil hydrolysis and its effect on $\gamma$-decalactone production, J. Am. Oil Chem. Soc. 89 (2012) 1041-1047.

[28] A.G. Ostel, J.G. Holt, Nile blue A as a fluorescent stain for poly-betahydroxybutyrate, Appl. Environ. Microbiol. 44 (1982) 238-241.

[29] D.P. Mesquita, C. Leal, J.R. Cunha, A. Oehmen, A.L. Amaral, M.A.A. Reis, E.C. Ferreira, Prediction of intracellular storage polymers using quantitative image analysis in enhanced biological phosphorus removal systems, Anal. Chim. Acta 770 (2013) 36-44.

[30] D.P. Mesquita, A.L. Amaral, E.C. Ferreira, Identifying different types of bulking in an activated sludge system through quantitative image analysis, Chemosphere 85 (2011) 643-652.

[31] A.L. Amaral, E.C. Ferreira, Activated sludge monitoring of a wastewater treatment plant using image analysis and partial least squares regression, Anal. Chim. Acta 544 (2005) 246-253.

[32] D.P. Mesquita, A.L. Amaral, E.C. Ferreira, M.A.Z. Coelho, Study of saline wastewater influence on activated sludge flocs through automated image analysis, J. Chem. Technol. Biotechnol. 84 (2009) 554-560.

[33] N. Gomes, M. Aguedo, J.A. Teixeira, Oxygen mass transfer in a biphasic medium: influence on the biotransformation of methyl ricinoleate into $\gamma$-decalactone by the yeast Yarrowia lipolytica, Biochem. Eng. J. 35 (2007) 380-386.

[34] D.R. Nielsen, A.J. Daugulis, P.J. McLellan, A novel method of simulating oxygen mass transfer in two-phase portioning bioreactors, Biotechnol. Bioeng. 83 (2003) 735-742.

[35] P.F.F. Amaral, M.G. Freire, M.H.M. Rocha-Leão, I.M. Marrucho, J.A.P. Coutinho, M.A.Z. Coelho, Optimization of oxygen mass transfer in a multiphase bioreactor with perfluorodecalin as a second liquid phase, Biotechnol. Bioeng. 99 (2008) 588-598.

[36] D. Gómez-Díaz, J.M. Navaza, B. Sanjurjo, Interfacial area evaluation in a bubble column in the presence of a surface-active substance: comparison of methods, Chem. Eng. J. 144 (2008) 379-385.

[37] E. Carvalho, E. Camarasa, L.A.C. Meleiro, R. Maciel Filho, A. Domingues, Ch. Vial, G. Wild, S. Poncin, N. Midoux, J. Bouillard, Development of a hydrodynamic model for air-lift reactors, Braz. J. Chem. Eng. 17 (2000) 4-7.
[38] M.K. Peter, A. Margaritis, M.A. Bergougnou, J.T. Yu, Influence of the baffle clearance design on hydrodynamics of a two riser rectangular airlift reactor with inverse internal loop and expanded gas-liquid separator, Chem. Eng. J. 121 (2006) 17-26.

[39] M. Blažej, J. Annus, J. Markoš, Comparison of gassing-out and pressure-step dynamic methods for $k_{L} a$ measurement in an airlift reactor with internal loop, Chem. Eng. Res. Des. 82 (2004) 1375-1382.

[40] T. Samuel, A. Cockx, A. Line, Global modeling of a gas-liquid-solid airlift reactor, Chem. Eng. Sci. 60 (2005) 5991-6003.

[41] T. Zhang, T. Wang, J. Wang, Analysis and measurement of mass transfer in airlift loop reactors, Chin. J. Chem. Eng. 14 (2006) 604-610.

[42] D. Zhonghuo, W. Tiefeng, N. Zhang, Z. Wang, Gas holdup, bubble behavior and mass transfer in a $5 \mathrm{~m}$ high internal-loop airlift reactor with non-Newtonian fluid, Chem. Eng. J. 160 (2010) 729-737.

[43] Y. Kawasse, M. Moo-Young, Influence of antifoam agents on gas hold-up and mass transfer in bubble columns with non-Newtonian fluids, Appl. Microbiol. Biotechnol. 27 (1987) 159-167.

[44] M.S. Saudi, J. Krishnan, T.H. Ling, M.V.P.S. Veluri, Enhancement of oxygen mass transfer and gas holdup using palm oil in stirred tank bioreactors with xanthan solutions as simulated viscous fermentation broths, Biomed. Res. Int. (2013), Article ID 409675.

[45] R.A.R. Bello, C.W.M. Moo-Young, Prediction of the volumetric mass transfer coefficient in pneumatic contactors, Chem. Eng. Sci. 40 (1985) 53-58.

[46] M. Barboza, M. Zaiat, C.O. Hokka, General relationship for volumetric oxygen transfer coefficient $\left(k_{L} a\right)$ prediction in tower bioreactors utilizing immobilized cells, Bioprocess. Eng. 22 (2000) 181-184.

[47] M. Ahuedo, N. Gomes, E.E. García, Y. Waché, M. Mota, J.A. Teixeira, I. Belo, Decalactone production by Yarrowia lipolytica under increased $\mathrm{O}_{2}$ transfer rates, Biotechnol. Lett. 27 (2005) 1617-1621.

[48] E.E. García, J.-M. Nicaud, J.-M. Belin, Y. Waché, Effect of acyl-CoA oxidase activity on the accumulation of $\gamma$-decalactone by the yeast Yarrowia lipolytica: a factorial approach, Biotechnol. J. 2 (2007) 1280-1285.

[49] N. Gomes, Biotransformation of ricinoleic acid into $\gamma$-decalactone by Yarrowia lipolytica: bioprocess optimization (PhD thesis), Braga, Portugal, 2011.

[50] E. Escamilla-García, S. O'Riordan, N. Gomes, M. Aguedo, I. Belo, J. Teixeira, J.-M. Belin, Y. Waché, An air-lift biofilm reactor for the production of $\gamma$-decalactones by Yarrowia lipolytica, Process Biochem. (2014), http://dx.doi.org/10.1016/j.procbio.2014.05.011.

[51] M. Aguedo, Y. Waché, V. Mazoyer, A.S.-L. Grand, J-M. Belin, Increased electron donor and electron acceptor characters enhance the adhesion between oil droplets and cells of Yarrowia lipolytica as evaluated by a new cytometric assay, J. Agric. Food Chem. 51 (2003) 3007-3011.

[52] P.J. Szaniszlo, Fungal Dimorphism with Emphasis on Fungi Pathogenic for Humans, Plenum, New York, 1985.

[53] A. Vanden Bossche, F.C. Odds, D. Kerridge, Dimorphic Fungi in Biology and Medicine, Plenum, New York, 1993. 